the tremendous costs of atom-smashing equipment. Not so many years ago requests for such would have received scant public consideration. Research on the potential utility of the great bulk of the world's plant population is where atomic research was 25 years ago. It is hoped that botanical scientists in general and economic botanists in particular can be more articulate in describing the needs and benefits of this type of research in relation to its benefits to mankind. If the objectives are comprehensible, financial and administrative support eventually will be found.

Loncwood Gardens,

Kennett Square, Pennsylyania

\title{
SOIL-PLANT RELATIONSHIPS AND PLANT NUTRITION
}

\section{A. G. Norman}

'THE SOLL ENVIronment.-Although it has been established beyond all doubt that higher plants can be successfully grown to maturity in the entire absence of soil if the root system is immersed in a nutrient solution composed of certain inorganic salts, the fact remains that soil is the normal root environment. Furthermore, the direction of evolutionary adaptation of plant roots must have been towards accommodation to the nutritional and physical environment provided by soils. It would be unwise to assume that in water culture or nutrient culture solutions higher plants necessarily find optimum conditions for growth. However, the use of such solution cultures has been of great value in determining which inorganic ions are essential for the welfare of the plant, and in particular in ascertaining those needed only in minute amounts. Solution culture systems have been particularly helpful in establishing and recognizing sumptoms of deficiency or unbalance of particular nutrients, because such symptoms can then be employed diagnostically on soils in which these nutrients may be in poor supply or unavailable. Puhlic interest was aroused a decade or so ago in the practical use of soil-less culture systems for the growth of flowers and vegetables. These went under a variety of names, such as "nutriculture," "hydroonics," etc. Although there are circumstances in which these may offer advantages over culture in soil, this usually arises from some factor not directly related to the growth or fruitfulness of the plant.

In addition to providing proof of the essentialit: of particular nutrient ions, solution culture methods have made it certain that higher plants have no requirement for organic substances for optimum growth, that they are not directly dependent on the mineral particles that constitute much of the solid phase of soils, and that micro-organisms, though ordinarily present in great numbers on root surfaces, are not essential for growth. There is a danger, however, in generalizing too broadly from such conclusions. One cannot safely assume from such experiments that under natural conditions in soil soluble organic substances present in the root zone may not enter the plant, or that there may not be interactions of nutritional importance between the surface of roots and mineral particles, or that micro-organisms in the close vicinity of roots are not involved in activities that affect plant growth. It has to be concluded therefore that plant physiological studies in nutrient solutions have certain limitations and that conclusions as to uptake mechanisms, etc., drawn therefrom, though wholly applicable to such circumstances, may not be completely valid or exclusively operate in the case of roots in soil.

Plant Requirements.-Plants have the capacity of synthesizing a bewildering array of organic compounds, many of great complexity. Some of the pathways of synthesis and interconversion are now becoming known. The effectiveness of the total operation, the total dry matter synthesized, or the size and fruitfulness of the plant, all are as depend. ent in ordinary circumstances on the quality of the soil and the nutritional and physical environment which it provides for the root system, as on factors such as light, carbon dioxide supply, and equable temperatures, that bear directly on the photosynthetic areas of the plant.

What does the soil provide that is essential to optimum plant growth? First, inorganic nutrient ions, second, water, and third, oxygen. For optimum growth an adequacy of each is necessary at all times; periods of inadequacy cannot usually be compensated for later, and are likely therefore to be reflected in a reduction of total seasonal growth.

It is difficult to express plant requirements for nutrients on a meaningful basis except in terms of soil area. In table 1 are given the quantities of the major nutrients present in an acre planting of certain crops. As will be discussed later, these amounts may be greater than the minimum requirements, because the content of nutrient elements in plants is related to the supply perhaps more than to the minimum needed. However, these figures are sufficient to indicate that types of land use which involve annual removal of much of the vegetation in volve also depletion of the nutrient resources at a substantial rate.

Plant requirements for water can be expressed either on an area basis, or in terms of the amount necessary to proc'uce a unit of dry weight. That the 
growth of plants in great areas of the world is limited by the inadequacy of the rainfall is wellknown, but the amount required by plants in humid areas is far greater than usually realized. More over, relatively short periods of inadequate supply are now recognized to bring about substantial depression in the total seasonal growth if they occur at a critical stage in the growth cycle of the plant. As with nutrients, the quantity of water used to maturity by plants is not necessarily the minimum requirement, and is influenced by such factors as air temperatures and humidities. On an area basis the amounts are large. Not infrequently the demand in a summer month may exceed the total rainfall less evaporation for that month, which means that, unless the storage capacity of the soil for water is considerable, there may be a period of inadequate supply. Expressed as weight of water required to produce a unit of dry plant tissue, the figures are also substantial. Some species are more efficient than others in water use, but in general $150-600$ pounds of water must be taken up and transpired for each pound of dry matter synthesized. Water is by far the most important plant nutrient quantitatively, and the ability of different soils to supply water greatly influences the array of native vegetation and the selection of crops and crop varieties that can be profitably grown when the land is farmed.

The requirements of plant roots for oxygen cannot be expressed in the same way as the requirements for nutrients or water, though for most species there is no question as to essentiality. Oxygen is needed to maintain aerobic cellular processes in root tissues, and, although small amounts of oxygen can reach the roots of some species from the tops through internal air spaces, the major source is from the soil atmosphere. Many attempts have been made to determine the composition of the soil atmosphere, and some objections have been raised to most of the procedures used, but even so it appears probable that ordinarilv the soil atmosphere does not differ greatly from the air above in amounts of the major components. The salient difference is

TABLE 1. Quantities of some nutrient elements in an acre planting of certain crops ${ }^{\text {n }}$

\begin{tabular}{lrrrrrrr}
\hline & & N & P & K & Ca & Mg & S \\
Crop & Yield & lb. & lb. & lb. & lb. & lb. & lb. \\
\hline Corn & 60 bu. & 93 & 17 & 55 & 17 & 7 & 11 \\
Oats & 50 bu. & 44 & 7 & 33 & 10 & 4 & 7 \\
Wheat & 25 bu. & 38 & 7 & 19 & 5 & 3 & 6 \\
Soybean & 20 bu. & 100 & 12 & 37 & 31 & 20 & 5 \\
Alfalfa & 4 ton & 180 & 19 & 148 & 148 & 30 & 19 \\
Sweet Potatoes & 300 bu. & 40 & 7 & 70 & 6 & 10 & 7 \\
Cotton & $1500 \mathrm{lb}$. & 75 & 11 & 45 & 64 & 14 & 12 \\
Sugar Beets & 15 ton & 76 & 10 & 50 & 22 & 7 & 5 \\
\hline
\end{tabular}

"These figures are the amounts absorbed at different locations by these crops in producing the yields indicated. thai the oxygen content may be a little lower, and the carbon dioxide content appreciably higher than in normal air. That the differences are not greater is due to the rapidity of gaseous diffusion and the continuous process of equilibration between the soil atmosphere and the infinitely large reserve in the air above. This means that the porosity of a soil really determines the oxygen supply to the roots, and that oxygen deficiencies are only likely in soils of low porosity or where the pores are filled with water to such an extent that gaseous diffusion is greatly hindered. Whereas air contains about 21 per cent oxygen, no adverse effects due to oxygen deficiency seem to develop in most species until the oxygen content of the root atmosphere is reduced to 5 per cent or less, if the carbon dioxide content is not excessive. Soil physicists have given much thought to the problem of expressing the capacity of a soil to supply oxygen to plant roots. The total pore space alone is not a satisfactory measure because the size and distribution of the pores determines the degree of "aeration" of a soil at different moisture levels. A fine-textured soil will have a greater pore space than a coarse sandy soil, but would not necessarily provide a better root environment insofar as oxygen supply is concerned. In the field aeration is largely determined more by the degree of aggregation of the individual soil particles into larger structural units, than by the size distribution of the component soil particles. Much of the interest in soil conditioners arises from the improved aeration that can result if the extent of aggregation of fine-textured soils is increased.

Micro-organisms IN solL.-If then the soil environment is one from which the plant derives nutrient ions, water and oxygen, how does it differ from an aerated water culture in which are present soluble salts supplying all the essential nutrient ions that ideally should meet plant requirements? The answer to this question could lead into a discussion of soil chemistry, and the forms in which the essential nutrient ions are presented to plant roots. However, it is pertinent at this stage to point out that any definition of soil should include the statement that it is characteristically the habitat for organisms other than higher plants, and that soils ordinarily contain extensive and diverse populations of microorganisms. The soil organisms are indeed potent as soil-forming agents, and higher plants are interlopers in an intensely active and competitive microbiological world. The living component of soils, its microflora and microfauna, constitutes a metabolic pool of nutrients. To a degree higher plants may be said to be dependent on some of the by-products and end-products of the activities of micro-organisms in the soil. Plant and animal residues, in or on the soil, are decomposed by micro-organisms. The nutrients which they contain are released for re-use. In nitrogen transformations the soil population plays a vital part, inasmuch as the only reserve of 
this element in the soil is in the organic form, unavailable to plants until mineralized.

Much more attention has been given to bacteria, fungi and actinomycetes in soils, than to protozoa and the other components of the soil fauna. Quantitative studies of the distribution of bacteria show that millions of organisms are present per gram of top soil. Such figures are often baffling unless it is recognized that a million bacterial cells, $I \mu$ by $0.5 \mu$ in size, would have a volume of only 0.0002 $\mathrm{mm} .{ }^{3}$ and that a gram of soil may have a volume of 0.8 cc. and a surface greater than $1 \mathrm{~m}^{2}$. More important, however, is the fact that the microbial cells are concentrated where there is food. In the vicinity of plant residues, or fragments of organic material, dense colonial growth may occur. Moreover, microbial cells, as they die, themselves form food for other organisms.

It has long been recognized that in the immediate vicinity of plant roots micro-organisms are particularly abundant. Indeed it would be correct to say that plant roots are virtually encompassed by a mịcrobial mantle. The zone immediately adjacent to plant roots, which has been called the rhizosphere, is therefore a zone of intense microbial activity. The organisms present seem often to be qualitatively as well as quantitatively different from those present at a distance from the roots. Furthermore, there is reason to believe that different plant species growing in the same soil do not have identical rhizosphere populations. These organisms presumably develop because soluble organic substances are liberated from plant roots, and different species may not liberate the same compounds. In a sense, plants may be said to determine their microbiological associates. In sterile systems a number of amino acids have been identified as coming from plant roots, but the physiology of this phenomenon has not been fully studied. Only from the ubiquity of rhizosphere populations can it be deduced that organic excretions, emanations, or exudations from plant roots are general.

There is no evidence that the rhizosphere population is in any way essential to plant growth. Growth in sterile soil or sterile nutrient solutions is at least as good as in non-sterile environments. However, this does not mean that the presence and activity of the rhizosphere population can be ignored when considering the nutrition of the plant. The microbiology, and presumably therefore the biochemistry of a cropped soil is quite different from that of a soil free of vegetation.

Some special relationships between soil microorganisms and plants ought to be mentioned here. The rhizosphere population at times contains pathogenic organisms that can directly injure root tissues. Most organisms of this type are relatively unspecific and cause injury to diverse plant species. The damping-off of seedlings is frequently due to the presence of pathogenic fungi. Root rots may be caused by bacterial invasion.

There are, however, beneficial relationships between soil organisms and plant roots that involve the transfer of nutrients. The best-known and in a sense the least understood of these is the case of the nitrogen-fixing bacteria (rhizobia) which invade and cause nodules to develop on the root system of some leguminous plants, and which, by synthesizing an organic nitrogen compound utilizable by the plants, release them from complete dependence on the supply of nitrate in the soil. The mycorrhizal relationship between certain fungi and many forest trees also is believed to affect the supply of one or more nutrients to the plant, the roots of which are invaded or enveloped by mycelial strands. The mycorrhizal association and the symbiotic system in leguminous plants, though beneficial, are not essential. Ecologically they can be of great importance because they may give the respective host plants nutritional advantages over other plants on the same site, which lack the capability of entering into these associations. But leguminous plants or normally mycorrhizal tree species if provided with an ample and complete nutrient supply will flourish and make optimum growth in the absence of the microbial partner.

NUTRIENT SUPPLIES AND RESERvES.-Returning to the question as to how a soil may differ from an aerated solution culture in supplying nutrient ions, water and oxygen to plant roots, one has to ask in what form the essential nutrients are found in soils. If they are all present in solution in the soil water, then in considering the soil as an environment for plant growth, it would only be necessary to study a water extract of soil, or the liquid phase, which is called the soil solution. For many years indeed the view prevailed that components on the mineral fraction of soils are slightly water-soluble, and that the supply of nutrients is maintained by solubility replenishment. Difficulties, however, arise in this viewpoint. Analyses of soil extracts or of the liquid phase of soils displaced by pressure or other means revealed very low concentrations of even those nutrients taken up in largest amounts. Although it may take 120 pounds of nitrogen per acre to make a $100 \mathrm{bu}$. corn crop, it is usually the case that on analysis there can only be found present at any one time 1-2 pounds of nitrate per acre. The nitrate level in the soil solution must therefore be renewed many times over in the course of a single season. Similar and even more striking is the situation encountered with phosphate which is almost always very low in concentration in the soil solution. To account for the total quantity present in a crop a rapid rate of renewal has to be presumed.

The composition of the soil solutions from soils differing greatly in fertility does not fall in line with the growth behavior of plants grown in these soils. Moreover, the quantities of soluble salts found seem 
to change greatly with the moisture content of the soil, often in an inconsistent manner. In determining the available supply of a particular nutrient in the soil, therefore, the amount present in the soil solution at any one time is not informative. The crux of the situation is the rate of its renewal or replenishment in the soil solution.

Truog has spoken of the soil as a "frugal custodian" of nutrients, and indeed on reflection, it will be realized that it is well that this is so. If there was a substantial supply of the necessary nutrients in soil in a soluble form, it would be very susceptible to loss by leaching in humid climates. Drainage waters would rapidy carry away nutrient elements as salts in areas where $20-50$ or more inches of water annually pass through the soil mass. It is true that there is some loss of plant nutrients from soil by leaching, and that soils in warm climates sub. jected to heavy rainfall become depleted, but even so the composition of the mineral and organic components of soils in general are such that the reserves of essential nutrients are protected against loss by their relative insolubility.

It has been one of the salient objectives of soil chemists to clarify the mechanisms by which unavailable nutrients become available to the plant. This has been a substantial task because the chemistry of each of the essential elements is different, and although there are certain similarities within groups of these elements, each one has had to be tackled as a separate problem. With some understanding of the transformations involved, the soil chemist has attempted to develop relatively simple procedures that provide some measure of the availability and therefore the probable release rate of the major essential nutrients, and has had some success in devising "quick" tests that can be used to predict whether or not supplementing the supply by use of a fertilizer would be economically advantageous. Wide use is now made of such tests by farm advisors, fertilizer companies, etc.

If the theory of dependence on the soil solution is inadequate to explain nutrient uptake in the soil, what alternative is there? It is believed by soil scientists that cations, or bases, such as calcium, magnesium or potassium can be directly exchanged from the surface of soil particles to the surface of a root in contact with it, without the necessity of being present as a salt in the intervening soil solution. Essentially the difference is that in contact exchange the base may be exchanged for hydrogen, whereas in the soil solution an accompanying anion must be present. The experimental proof of the validity of the contact exchange theory has presented many difficulties. It is not a matter of proving one correct and the other incorrect. Both mechanisms may be operative simultaneously, both may be in equilibrium. The system may be complicated by the presence of micro-organisms, the surface of which similarly may enter into exchange reactions, and the activities of which may add products to the soil solution.

The CLAY COLLOIDS.-Soils are formed by the weathering of the parent rocks, and the process of weathering involves extensive chemical changes. The minerological composition of a soil may not be easy to determine and the proportion of recognizable minerals present, other than quartz, is often not high. The clay component, arbitrarily taken as that fraction less than $2 \mu$ in size, is colloidal in character with a high ratio of surface to mass, and is largely synthesized during the process of weathering. The type of clay depends on the chemistry of the parent rock and the intensity of the weathering processes. Clays are complex insoluble aluminosilicates, the structure of which is built around tetrahedra of aluminum or silicon linked through oxygen or to hydroxyls. They are micro-crystalline in the sense that there is regularity of arrangement in planes, which regularity is not destroyed by isomorphic substitution, consisting of partial replacement in the crystal lattice by other elements. Clays are in effect insoluble acids bearing a negative charge which can be neutralized by hydrogen ions or other cations. In a neutral soil the clay colloids are fully saturated with bases, whereas in an acid soil there is partial hydrogen replacement. It is these cations which are available for exchange with plant roots, and it is the clay complex that constitutes the reserve of these cations.

Several different types of clay colloid have been recognized, and even within a single type there is some range in properties. However, the different types behave as though they were different kinds of insoluble acids. They have different total exchange capacities, and the ease of replacement of various cations retained by them may be different. In equilibrium with an extracting solution, or with plant roots, the partition of exchangeable bases would not be the same. Some of the major differences between soils in physical properties and nutritional properties are explicable only on the basis of the different types of clay which they contain.

The total exchange capacity of a soil depends primarily on the amount and nature of the clay component. The organic fraction of soils also possesses the property of retaining cations by attachment to carboxyl and hydroxyl groups, and in soils of high organic content the fraction of the total exchange capacity due to the organic matter may exceed that due to the clay. Examples of the exchange capacity of some representative soils are given in table 2 .

The array of bases present in substantial amounts includes calcium, magnesium, potassium and sodium, usually in descending order quantitatively. Calcium usually far outweighs the other bases, and calcium and magnesium together may account for 90-95 per cent of the total exchangeable bases. In a soil with a total exchange capacity of 15 milli- 
TABLE 2. Cation exchange capacities of some representative surface soils

\begin{tabular}{|c|c|}
\hline & $\begin{array}{c}\text { Exchange Capacity } \\
\text { m.e. } / 100 \text { g. }\end{array}$ \\
\hline Cass Sandy Loam, Nebraska & $5.7^{\mathrm{a}}$ \\
\hline Wabash Silty Clay Loam, Nebraska & $16.8^{a}$ \\
\hline Marshall Silty Clay Loam, Nebraska & $17.1^{\AA}$ \\
\hline Sharpsburg Silty Clay Loam, Nebraska .. & $21.5^{\star}$ \\
\hline Crete Silty Clay Loam, Nebraska & $22.6^{\mathrm{a}}$ \\
\hline Pima Clay Loam, Arizona & $40.5^{b}$ \\
\hline Mohave Sandy Clay Loam, Arizona & $18.5^{b}$ \\
\hline Tucson Sandy Loam, Arizona & $9.7^{b}$ \\
\hline Laveen Sandy Loam, Arizona & $6.4^{b}$ \\
\hline Davidson Loam, N. C. & $22.9^{\mathrm{e}}$ \\
\hline Hiwassee Clay Loam, N. C. & $22.3^{\mathrm{c}}$ \\
\hline Utuado Sandy Loam, P. R. & $10.7^{\mathrm{d}}$ \\
\hline Mucara Sandy Loam, P. R. & $30.9^{\mathrm{a}}$ \\
\hline
\end{tabular}

a Lipps, R. C., and L. Chesnin. 1950. Soil Sci. Soc. Amer. Proc. 15: 329-333.

${ }^{b}$ Flocker, W. J., and W. H. Fuller. 1956. Soil Sci. Soc. Amer, Proc. 20: 387-39I.

c Nyun, M. A., and S. B. McCaleb. 1955. Soil Sci. 80: 27-41. 420.

abruna, F., And R. M. Smith. 1953. Soil Sci. 75: 411-

equivalents per $100 \mathrm{~g}$. with calcium accounting for 60 per cent of the exchangeable bases, there would be $3600 \mathrm{lb}$. exchangeable calcium per acre to the depth of six inches. If potassium accounted for 3 per cent of the exchangeable bases, there would be approximately 350 pounds of exchangeable potassium in the same volume of soil. These amounts are far more substantial in relation to the amounts taken up by an acre planting than are the quantities found in the soil solution at any one time. However, a total analysis of the soil would show much larger amounts of such elements as magnesium and potassium, and, although the nonexchangeable form is not directly available to plants, these nutrients are slowly released to replenish the supply of the exchangeable form as this is depleted by continual removal of vegetation. This is particularly important in the case of potassium, which often forms the major inorganic component of plant tissue, and yet which is not ordinarily a major exchangeable base. The chemistry of soil potassium indeed presents some unusual features, which have been much studied, because even drying and subsequent wetting of clays has been found to change the partition of potassium between exchangeable and non-exchángeable forms.

Much more could be said about the properties of the clay and organic colloids of soils, but it is sufficient here to indicate that the salient and outstanding difference between soils and nutrient solutions as environments for the growth of plants lies in the form of presentation of cations, the major ones, such as potassium and calcium, and minor ones, such as iron, manganese, zinc and copper.

However, not all the major nutrient ions are cations. There is yet to be accounted for such ions as nitrate, phosphate, sulphate and borate. Nitro- gen availability in soils ordinarily depends on a sequence of microbiological transformations. The soil nitrogen reserves are wholly organic, and the rate of release therefrom is controlled by the activity of an array of organisms, mostly unspecialized. The primary end-product is the ammonium ion, which is retained by clay and organic colloids, as are the other bases, and which can be exchanged with root surfaces and utilized directly by some plants.

However, microbial conversion to nitrate ordinarily takes place; it is usually not possible to find more than a trace of ammonia in soils. The ratelimiting step is the liberation of ammonium from the organic reserve, not the oxidation of ammonium to nitrate. The nitrate ion, accompanied by a cation from the exchangeable bases, is found in the soil solution. It does not appear to be retained in any way by the clay colloids. Soil clays do exhibit anion exchange reactions, somewhat similar to cation exchange reactions, but at a lower level quantitatively and probably of significance only with such anions as phosphate and molybdate. The sulfate and chloride ions, like nitrate, do not enter into exchange with clays, because they are unable to replace lattice hydroxyls.

UPTAKE MECHANISMS IN PLANTS.-Up to this point the discussion has dealt primarily with the forms in which the major plant nutrients are present in soils, and hardly at all with the mechanism by which these nutrient ions are taken up by plants. The assumption has been made that, if an essential nutrient ion is present in the root zone, it can readily enter the plant. The mechanism of nutrient uptake has turned out to be a much more difficult problem than was thought earlier to be the case, and, although much progress has been made recently, especially through the use of radioisotopic tracers, explanations wholly acceptable to all investigators still remain to be developed. For reasons of simplicity uptake experiments are almost invariably carried out in simple salt solutions, and frequently at ionic concentrations considerably greater than encountered in the soil solution. Such experiments, though informative up to a point, are likely to be incomplete. Furthermore, experiments on uptake carried out with whole plants inevitably also became transport experiments in which it is difficult to separate those processes involved in primary entry from those involved in subsequent movement of the ions that have been taken up.

There are certain generalizations about the uptake of ions by plants that should be made.

(1) Ion uptake is selective, but very imperfectly so. Ions are not taken up strictly in proportion to the relative concentrations present in the root environment, nor is uptake limited to those ions that are essential for plant growth. Non-essential ions can be taken up in substantial amounts and may compete with the uptake of essential ions. 
(2) Essential ion uptake is not related to the immediate or total quantitative requirement of the plant. The amount which enters is greatly influenced by the supply in the environment, not by the needs of the plant. There may be uptake greatly in excess of the requirement for optimum growth. This phenomenon is known as "luxury consumption." Luxury consumption is, however, a relative matter. In practice the supply of one or more critical elements may limit growth; the remainder then may be in the zone of luxury consumption. If the supply of the limiting nutrient is later increased, the circumstance with respect to those formerly in excess may be quickly changed.

(3) Ion uptake by different species of plants given the same nutrient environment is often very different quantitatively. This fact has to be accommodated in any theory of the mechanism of uptake.

(4) Continued ion uptake and accumulation is a property only of living and respiring roots. If added to a nutrient solution, certain metabolic inhibitors, which halt cellular respiratory processes, will prevent ion uptake, as will withdrawal of oxygen or depression of temperature.

(5) The mechanisms of uptake of cations and anions are not identical, nor are they inter-dependent. Whereas anion uptake is certainly "active" in the sense that it is an energy-consuming process, there is some controversy as to whether cation accumulation involves the expenditure of energy, though an actively metabolizing cellular system is required.

It has been found recently that some revision of the classical concept of a root is necessary. Instead of picturing the external cells of roots as forming a continuous semi-permeable membrane through which must pass the nutrients, water and oxygen necessarv for plant growth, there is now considerable evidence for the view that an external solution can freely penetrate some parts of the root tissue. This region. accessible by simple diffusion, has heen described as the "apparent free space," the "free space" or, somewhat ambiguously, the "outer space." The cells of some micro-organisms have similarly been shown to contain certain areas or space, the liquid in which comes quickly into equilibrium with the external solution. Reversible diffusion studies give information as to the volume of this space in roots. In some roots as much as one third of the root volume has been shown to be accessible. The most carefuly determined value is 23 per cent for the roots of young barley seedlings. This free space has not been defined histologically. The obvious suggestion would be that the free space consists of connecting intercellular spaces forming a ramifying system through the root. There is, however, reason for thinking that the accessible regions may involve some part of the cell cytoplasm.
The importance of this concept of an accessible free space in plant roots is that the liquid in the free space may be that from which all active ion accumulation takes place. However, this liquid may contain soluble substances of cytoplasmic origin which then would be capable of "leaking" from roots. Those root exudations or emanations that provide the substrate for the rhizosphere population may have this origin.

If the liquid in the free space is in equilibrium with that outside the roots, then it might appear that the soil solution theory would be adequate to account for the nutrition of the plant, and that interest in the exchangeable base system of the soil colloids would be limited only to its effect on the concentration of cations in the soil solution with which it would be in equilibrium. This has to be modified, however, because root surfaces are capable of retaining cations, and have a measurable and rather high cation exchange capacity comparable to, but not identical with that exhibited by the clay and organic colloids of the soil. This cation exchange capacity can be determined by meihods similar to those used for soil, or by titrating electrodialyzed plant roots. The basis of expression leaves something to be desired, but the figures in table 3 attest to the activity of root surfaces, and to the important fact that the roots of different plant species may vary widely in ability to retain cations. Perhaps it is not coincidence that leguminous plants, which are high accumulators of cations, have roots of high cation retaining capacity. It is important to point out here, however, that the methods used for determining the exchange capacity of roots will include sites throughout the free space, in addition to those on the external surfaces of the roots. Direct contact. exchange of bases on the soil colloids would presumably only be possible with the external surfaces. Root surfaces and clay colloids in contact would come to an equilibrium which would depend on the relative ease of replacement of cations on the two insoluble exchange systems.

The processes of diffusion and cation exchanges are essentially physical and involve no expenditure of energy by the cell. Both will proceed at low temperature or in an inert gas. No ion specificities characteristic of the special requirements of the plant are evident in these steps.

The key process of ion accumulation, which is partially selective and which does involve a metabolic mechanism, has been a recalcitrant problem for the plant physiologist. Its full solution vet awaits further clarification of the biochemical events within plant cells. However, the view which is gaining wide acceptance is that the essential feature in uptake is a binding of the ion with a carrier, the carrier being a compound, perhaps analogous to an enzyme, produced by the cell. Carriers are presumed to exist for both anions and cations and to possess specificity or selectivity for 
TABLE 3. Cation retention capacity of plant roots

\begin{tabular}{|c|c|c|c|}
\hline Species & $\begin{array}{l}\text { m.e. per } 100 \mathrm{~g} . \\
\text { dry roots }\end{array}$ & Species & $\begin{array}{l}\text { m.e. per } 100 \mathrm{~g} \text {. } \\
\text { dry roots }\end{array}$ \\
\hline Soybean & $58.9^{\mathrm{a}}$ & Rye & $15.1^{\mathrm{a}}$ \\
\hline Red clover .... & $47.9^{\mathrm{a}}$ & Barley & $12.3^{\mathrm{a}}$ \\
\hline Ragweed & $58.9^{\mathrm{a}}$ & Alfalfa & $41.4^{b}$ \\
\hline Potato & $38.1^{\mathrm{a}}$ & Soybean & $41.1^{b}$ \\
\hline Tomato & $34.6^{\mathfrak{a}}$ & Redtop & $14.1^{b}$ \\
\hline Corn & $26.0^{a}$ & Reed canary & \\
\hline Orchard grass & $25.6^{\mathrm{a}}$ & grass & $11.8^{b}$ \\
\hline \multirow[t]{2}{*}{ Timothy } & $22.6^{\mathrm{a}}$ & Buckwheat & $38.7^{\circ}$ \\
\hline & & Oats & $18.8^{\circ}$ \\
\hline
\end{tabular}

"By electrodialysis and titration. DRAKE, M., J, VENGRIS, A ND W. G. Colby. Soil Sci. 72: 139-147. 1951.

${ }^{b}$ By electrodialysis and titration. MCLean, E. O. AND

F. E. Baker. Soil Sci. Soc. Amer. Proc. 17: 100-102. 1953.

'By electrodialysis and titration. McLean, E. O., AND

D. Adams. Soil Sci. Soc. Amer. Proc. 18: 273-275. 1954.

particular ions, but this specificity is not absolute and ions of other elements chemically related in the periodic table may also be bound. The carrier-ion complex is then presumed to be able to pass through some form of barrier or membrane not permeable to the ion alone. Once in this "inner" space the ion is again released in an irreversible step. The barrier is considered to be quite impermeable to the free ions because, if an ion is once absorbed, it does not then exchange with an isotopically enriched solution containing the same ion. Such "accumulated" nutrients are not subsequently free to move as long as the cells are active.

The evidence for the existence of ion carriers is wholly indirect. It finds support in kinetic studies, and in the parallelism shown with enzyme-substrate mechanisms. The synthesis of the carriers is assumed to be dependent on the respiratory process in the cell, but interactions are suspected, thus complicating the picture. That is, one ion may be essential in the synthesis of a carrier for another ion, or even may constitute a part of the carrier complex for another ion.

This theory calls for the uptake of all ions to be dependent upon metabolically synthesized ion carriers. A more restricted theory links anion uptake with the operation of the cytochrome system and regards cation uptake as incidental by exchange for the hydrogen ions liberated in the cell. Inhibitors of cytochrome oxidase activity quench active uptake, but cellular metabolic processes are so interrelated and interdependent that caution has to be exerted in ascribing specific roles to particular mechanisms.

There still remains much to be clarified in the basic process of nutrient uptake and in accounting for root behavior in the nutritional environment provided by soil. There seems to be some doubt among some plant physiologists as to whether the cation exchange capacity of roots is of any consequence, and whether exchange to such sites constitutes any essential part of the ion absorption process. Because they lack specificity, the cation retaining sites of plant roots are not believed to be those involved in active uptake; moreover, some are external and some are internal. Most experimentation on nutrient uptake is carried out using very young seedlings immersed in simple salt solutions containing a large excess of the ion under study. By diffusion the free space rapidly comes into equilibrium, and by exchange the cation retention sites become extensively filled with the cations supplied. The situation in soil may be very different because there the external sites at least will directly reflect the cation array on the soil colloids, through equilibration this will result in a modification of the composition of the soil solution in immediate contact with the external surface of the roots and therefore by diffusion that of the solution in the free space.

Ultimately it should be found possible to reconcile and incorporate in a unified scheme the soil solution theory of plant nutrition in soils and the contact exchange theory. As with the soil population where that in the immediate vicinity of the roots is recognizably different from that at a distance, so it is likely that the soil solution in the immediate vicinity of roots may be substantially modified by the presence of ions on the surfaces of the root and the micro-organisms thereon. The equilibrium reached is likely to be a complex one between the surfaces of clay and organic colloids on the one hand, and actively metabolizing root tissues and micro-organisms on the other.

\footnotetext{
Department of Botany and Botanical. Gardens, UNIVERSITY OF MiChIGAN, ANn Arbor, Michigan
} 